\title{
Ana Beraldo
}

Universidade Federal de Minas Gerais, Belo Horizonte, MG, Brasil

\section{Telma de Souza Birchal}

Universidade Federal de Minas Gerais, Belo Horizonte, MG, Brasil

\section{Claudia Mayorga}

Universidade Federal de Minas Gerais, Belo Horizonte, MG, Brasil

\section{O aborto provocado: um estudo a partir das experiências das mulheres}

\begin{abstract}
Resumo: Este artigo expõe resultados de uma pesquisa realizada entre 2013 e 2015 que visou à compreensão dos aspectos de experiências de um grupo de mulheres que fizeram aborto clandestino. Os casos estudados envolveram mulheres com alto nível de escolarização, as quais, em sua maioria, haviam participado de movimentos feministas, um perfil diferente daquele que tem sido objeto da maior parte dos trabalhos relatados na literatura. Foram realizadas entrevistas em profundidade com oito mulheres que interromperam a gravidez. A partir das análises, são apresentadas as motivações, as dúvidas e as certezas presentes no processo de tomada de decisão pelo aborto, bem como a influência do envolvimento com o feminismo nesse processo.
\end{abstract}

Palavras-chave: aborto; maternidade; sexualidade; experiência

\section{Introdução}

O aborto provocado é um tema que suscita polêmica. Sendo legal em somente três situações no Brasil (caso de estupro, risco de morte para a grávida e anencefalia fetal), ${ }^{\prime} 0$ debate sobre a ampla legalização do aborto tem sido uma constante na sociedade e 
quase certamente leva a uma querela acalorada: ou se é a favor ou contrário à legalização do procedimento. Independentemente disso, o aborto é prática frequente no Brasil. ${ }^{2}$

Diante desse cenário, torna-se interessante conhecer e compreender melhor as experiências de mulheres que interromperam a gravidez, sobretudo quando se leva em conta a existência, na nossa sociedade, de uma íntima associação entre maternidade e feminilidade. ${ }^{3}$

Simone de BEAUVOIR (2004), em sua famosa obra O Segundo Sexo, de 1949, afirma que a mulher é pensada sempre em relação ao homem, sendo o homem sujeito, o essencial, e a mulher o outro, não essencial. Assim, diante do homem racional, viril, destemido, tem-se a mulher delicada, amorosa, emotiva. Diante do homem trabalhador, político, tem-se a mulher cuidadora; tem-se, acima de tudo, a mãe. A autora busca desnaturalizar os lugares socialmente ocupados por homens e mulheres, negando a imposição biológica como determinante do destino das mulheres: não se nasce mulher, torna-se mulher.

De maneira similar, Elizabeth BADINTER (1985), no livro Um Amor Conquistado: o mito do amor materno, de 1980, analisa o chamado instinto materno em diferentes momentos da história. Por meio de um resgate temporal, a autora mostra que o papel da mulher na família nem sempre foi o mesmo, bem como o papel do homem e o da criança. As relações dentro dessa triangulação sofreram mudanças importantes conforme se alteravam também os contextos sociais, espaciais e temporais. Foi a partir do século XVIII que o amor materno passa a ser concebido como algo presente em toda mulher em relação a seus filhos, e que o instinto materno passa a ser considerado tanto como natural quanto como santificado.

Pierre BOURDIEU (1998), no livro A dominação masculina, afirma que a reiteração perene das diferenças sexuais Ihes atribui um caráter de natureza incontestável, produzindo sujeitos que a elas se adéquam.

É a naturalização das diferenças sexuais que torna difícil transformá-las. As aparências biológicas e os efeitos, bem reais, que um longo trabalho coletivo de socialização do biológico e de biologização do social produziu nos corpos e nas mentes conjugam-se para inverter a relação entre as causas e os efeitos e fazer ver uma construção social naturalizada (os "gêneros" como habitus sexuados), como o fundamento in natura da arbitrária divisão que está no princípio não só da realidade como também da representação da realidade [...] (BOURDIEU, 2003 [1998], p. 9-10).

É verdade que, com o avanço de tecnologias na área de reprodução e contracepção, com especial destaque para o advento da pílula anticoncepcional no ano de 1960, a distinção entre sexualidade e reprodução passa a ser cada vez mais plausível. A partir dos anos 1970, a utilização dessas novas tecnologias passou a ser interpretada pelo feminismo como uma ruptura com a premissa tota mulier in utero, que definia a mulher pela sua capacidade de gestação (Lucila SCAVONE, 2001).

Assim, diante da recente convivência entre o cenário de hegemonia do ideal da mulher-mãe e o processo de desnaturalização da maternidade, acompanhado do crescimento da importância de aspectos outros da vida da mulher, torna-se interessante conhecer e compreender melhor as experiências de mulheres que interromperam a gravidez. São essas experiências o foco de interesse do presente trabalho.

As mulheres que atuaram como interlocutoras são, em sua maioria, de alta escolaridade, pertencentes à classe média, e com envolvimento com os movimentos feministas. Buscou-se compreender o processo da tomada de decisão pelo aborto e a forma como essa vivência foi significada pelas mulheres posteriormente.

${ }^{2}$ No Brasil, uma em cada cinco mulheres aos 40 anos já abortou ao menos uma vez (Débora DINIZ \& Marcelo MEDEIROS, 2012).

${ }^{3}$ Sobre essa associação e a forma como ela foi construída durante a Modernidade, ver Sally SHUTTLEWORTH (1990). 


\section{Procedimentos metodológicos}

Pesquisar sobre aborto no Brasil é pesquisar um fenômeno ilegal e estigmatizado, e, por isso, trata-se de um desafio. Dificuldades aparecem desde 0 início, no acesso às mulheres, e continuam ao longo de todo o percurso da pesquisa, na interlocução com elas estabelecida e na análise das entrevistas. Assim, foram necessários alguns cuidados metodológicos. Primeiramente, optamos por entrevistar mulheres que faziam parte dos círculos de convivência de pessoas conhecidas pelas pesquisadoras. Essa medida teve em vista o estabelecimento de uma relação que permitisse maior conforto às entrevistadas em compartilhar suas vivências. Uma vez estabelecido o primeiro contato com as entrevistadas, foi necessário um constante exercício de afastamento da dicotomia característica do debate público sobre o aborto para que elas se sentissem acolhidas e para que a dimensão da experiência emergisse com o mínimo possível de julgamento. Oito mulheres foram entrevistadas. As entrevistas, de caráter semiestruturado (Uwe FLICK, 2004), foram transcritas e analisadas através da Análise de Conteúdo (Laurence BARDIN, 2011 [1977] e FLICK, 2004).

As entrevistas foram realizadas em locais escolhidos pelas próprias entrevistadas. Algumas se deram em espaços públicos (lanchonetes, livrarias), outras nas casas das mulheres, e houve, ainda, entrevistas realizadas por Skype nos casos em que as interlocutoras moravam em outras cidades.

A partir das falas das entrevistadas, foram percebidos alguns eixos principais de sentido. Dentro de cada um desses eixos, foram identificadas categorias que indicaram os principais aspectos das experiências das entrevistadas, bem como o modo como esses aspectos se inter-relacionam (BARDIN, 2011 [1977]).

\section{Apresentação das entrevistadas}

As entrevistadas eram maiores de idade, com profissões diversas, relações variadas com o parceiro e alta escolaridade. A maior parte delas se declarou militante de movimentos feministas. Os nomes utilizados são fictícios, visando à preservação das participantes.

Tabela 1 - Características das entrevistadas

\begin{tabular}{|c|c|c|c|c|c|c|c|c|c|}
\hline Nome & \multicolumn{3}{|c|}{$\begin{array}{l}\text { Idade na } \\
\text { ocasitio }\end{array}$} & $\begin{array}{l}\text { Idade } \\
\text { atual }\end{array}$ & Profissiono & Escolaridade & \multicolumn{3}{|c|}{ Relaçăo com parceiro } \\
\hline Axaltia & \multicolumn{3}{|l|}{30} & 60 & $\begin{array}{l}\text { Aposentada } \\
\text { (funcionáris } \\
\text { pública) }\end{array}$ & E.S.C. & \multicolumn{3}{|c|}{ Năo sabia quem era o pai } \\
\hline Ester & \multicolumn{3}{|l|}{42} & 60 & $\begin{array}{l}\text { Aposentada } \\
\text { (funcionária } \\
\text { pública) }\end{array}$ & E. S. C. & \multicolumn{3}{|l|}{ Namorado } \\
\hline Francisea & \multicolumn{3}{|l|}{27} & 27 & Artista & E. S. L & \multicolumn{3}{|c|}{ Ex-namorado } \\
\hline Gebrgia & 23 & 28 & 35 & 53 & $\begin{array}{l}\text { Assistente } \\
\text { Social }\end{array}$ & E. S. C. & Namorade & Namorado & Marido \\
\hline Geovaana & \multicolumn{3}{|l|}{23} & 24 & Dençarina & E. S. C. & \multicolumn{3}{|l|}{ Namorado } \\
\hline Gerasa & 18 & 3 & & 43 & Doutoranda & E. S. C. & Nho sabia qu & m era opai & Marido \\
\hline Rose & \multicolumn{3}{|l|}{32} & 34 & Antropöloga & E. S. C. & \multicolumn{3}{|l|}{ Pontual } \\
\hline Lenita & \multicolumn{3}{|l|}{23} & 54 & $\begin{array}{l}\text { Professoca } \\
\text { universitíria }\end{array}$ & E. S. C. & \multicolumn{3}{|l|}{ Pontual } \\
\hline
\end{tabular}


Com vistas a sustentar uma visão mais bem contextualizada das vivências das interlocutoras, apresentamos, a seguir, resumidamente, cada uma das participantes.

Francisca é estrangeira, mas já há alguns anos vive no Brasil. Trabalha com diversos tipos de arte e leciona espanhol. Embora não passe necessidade, vive com pouco dinheiro. Foi criada sem religião, mas sua família não nuclear é católica. Francisca namorou um rapaz com o qual brigava muito. Depois que o relacionamento acabou, descobriu-se grávida e abortou. Ela foi a entrevistada cujo abortamento tinha sido mais recente (poucos meses antes da entrevista). Francisca se autodeclara branca. Tem contato com diversos movimentos sociais, estando familiarizada com os debates feministas.

Geovanna é filha de pais professores e tem uma avó muito católica. Ela mesma, no entanto, não foi criada dentro de nenhuma religião. Geovanna cresceu no interior de São Paulo e fez faculdade no interior de Minas Gerais. Na faculdade, se envolveu com o movimento estudantil e com movimentos feministas. Logo após a formatura, mudou-se para Belo Horizonte para construir a carreira. Geovanna estava morando com amigos quando engravidou do namorado e abortou. Se autodeclara branca.

Rose é antropóloga, filha de mãe católica e pai espírita. Participou do movimento político pela descriminalização do aborto. Já foi casada durante alguns anos, época na qual tentou engravidar, mas não conseguiu. Rose passou por um processo depressivo, período em que conviveu com problemas de acne, e tomou um remédio fortemente contraindicado para grávidas, o Roacutan. Pouco depois de melhorar da depressão, desempregada e ainda tomando o medicamento, aos 32 anos idade, encontrou com um conhecido no carnaval e engravidou. Ela morava e continua morando com sua mãe e seu irmão. Rose se autodeclara parda.

Gerusa cresceu em uma capital nordestina, em uma família evangélica de classe popular. Ela tem seis irmãos e sua infância e adolescência foram marcadas pela violência vivida dentro de casa. No fim da adolescência, afastou-se da igreja. Nesta época, aos 18 anos de idade, engravidou e não sabia quem era o pai. Fez o primeiro aborto. Algum tempo depois, mudou-se de cidade, fez faculdade e casou-se com um homem mais velho, que era médico. Quando se preparava para o mestrado, engravidou novamente, 20 anos depois da primeira gravidez, e abortou pela segunda vez. Gerusa nunca teve desejo de ter filhos. Hoje em dia, vive com um companheiro. Ela estuda relações étnico-raciais, classe e gênero, e tem contato com os movimentos negro e feminista. Atualmente, Gerusa se considera ateia. Ela se autodeclara negra.

Lenita, por morar em outra cidade, me concedeu entrevista via Skype. Ela cresceu no estado de São Paulo, em uma família católica, embora ela mesma não tivesse as mesmas práticas religiosas da mãe. Segundo Lenita, sua mãe era inteligente e tinha tino para os negócios, tendo ajudado a construir o patrimônio da família. Antes de se casar, a mãe trabalhava, mas abriu mão disso para se dedicar aos filhos e ao marido, o que Lenita não considera justo. Lenita, assim como Gerusa, não tinha desejo de ser mãe. Lenita namorava uma moça quando engravidou, aos 23 anos de idade. Nessa época, tinha conflitos em relação à sua sexualidade. Abortou e, logo depois, mudou de cidade, participou da fundação de um grupo feminista e construiu sua carreira. Atualmente, Lenita se considera lésbica. Ela afirmou não ter religião e se autodeclara branca.

Geórgia também foi entrevistada via Skype. Considera que sua família de origem era liberal. Ao longo da vida, teve cinco filhos, quatro adotados e um biológico. Geórgia começou a se envolver com o movimento feminista na adolescência. É fundadora de um grupo feminista que já existe há mais de 30 anos. Aos 23 anos, quando era estudante universitária e vivia com os pais, engravidou de um namorado do qual não gostava muito, e abortou pela primeira vez. Depois de formada, ainda vivendo com os pais, envolveu-se 
com um homem que havia acabado de se separar da esposa. Ela era apaixonada por ele, mas ele parecia não corresponder. Engravidou, e abortou pela segunda vez, agora com 28 anos. Quando já estava com uma situação de vida mais estável profissionalmente, depois de já ter tido os cinco filhos, engravidou de novo do marido. Abortou pela terceira vez, aos 35 anos. Geórgia se autodeclara branca e sem religião.

Azaleia cresceu em uma família conservadora do interior de Minas Gerais. Sua mãe casou-se duas vezes: ficou viúva do primeiro marido com cinco filhos e, depois, se casou de novo, e teve mais dois - Azaleia e um irmão - e divorciou-se. Azaleia trabalhava como funcionária pública e hoje em dia é aposentada. Engravidou, aos 30 anos de idade, de um namorado, quando a relação entre eles já estava estremecida. Ele estava envolvido com outra pessoa. Nesse período, ela havia se relacionado também com um amigo e não sabia qual dos dois era o pai. Considera-se agnóstica e se autodeclara parda.

Ester também trabalhava como funcionária pública e, atualmente, é aposentada. Tem seis irmãos e sua família de origem é conservadora e religiosa. Aos 42 anos, saiu da casa dos pais para morar sozinha, o que não foi bem aceito pela família, ocasionando, segundo ela, um processo depressivo em sua mãe. Na mesma época, começou o namoro com o homem com quem é casada atualmente. Engravidou sem querer, e abortou. Depois disso, tentaram ter filhos e não conseguiram. Ester é católica. Declarou-se como "morena clara".

\section{As entrevistas}

\section{Análise das entrevistas}

As análises que serão expostas a seguir estão organizadas em seis eixos de sentido. O primeiro é o das "Motivações", no qual os elementos elencados pelas entrevistadas como importantes para a tomada de decisão pela interrupção da gravidez são apresentados. O segundo eixo trata do momento 'd'“A decisão"', das dúvidas e certezas experimentadas pelas entrevistadas. O terceiro, que chamamos "O papel do feminismo na decisão", aborda como o envolvimento das mulheres com os movimentos e debates feministas influenciou suas experiências. Em seguida, no quarto eixo, é abordada a "Rede de relações" construída durante o processo do aborto, tanto no momento de tomada de decisão, quanto na concretização do procedimento. O quinto eixo relaciona-se aos "Sentimentos envolvidos" em todo o processo. O sexto e último eixo, denominado "Falar no assunto", trata do momento posterior ao abortamento e da forma como o evento é significado nas vidas das mulheres.

Como o número de situações de aborto é maior do que o número de entrevistadas, uma vez que Geórgia abortou três vezes e, Gerusa, duas, sempre que uma categoria for mencionada, haverá entre parênteses dois números - o primeiro representa a quantidade de entrevistadas, e o segundo representa a quantidade de situações de aborto que se encaixa naquela categoria.

\section{Motivações}

Primeiramente, as entrevistadas se dividem em dois grupos: as que não queriam ser mães ${ }^{4}(2 / 3)$ - Gerusa e Lenita - e as que tinham ou já haviam experimentado o desejo de ser mãe (6/9), que diz respeito à maioria das entrevistadas. As duas participantes que não queriam ser mães afirmaram que não sentiram esse desejo ao longo de suas vidas. Gerusa associa essa ausência de vontade de ser mãe a uma priorização de outros

\footnotetext{
${ }^{4}$ Tudo que está em negrito corresponde a uma categoria.
} 
objetivos em sua vida, como o de sair de um contexto de violência e o de continuar os estudos. Já Lenita cita o exemplo de sua mãe, a qual, apesar de muito inteligente, dedicouse exclusivamente aos filhos e ao marido ao longo da vida. Nesses casos, o aborto configura uma solução para o problema de terem engravidado na ausência do desejo pela maternidade.

Então eu lembro que desde os meus dez anos de idade, que eu falava assim 'Um dia eu vou embora daqui, um dia eu vou embora daqui', então o meu grande sonho era ir embora da casa dos meus pais, não era essa coisa de casar... (Gerusa)

Interessantemente, nenhuma das entrevistadas que tinha ou já havia tido o desejo de ser mãe abordou a origem deste desejo, o que talvez possa indicar, por um lado, uma naturalização da mulher como mãe em potencial. No entanto, por outro lado, várias ressaltaram que a maternidade não é essencial na vida de uma mulher $(4 / 5)$.

As entrevistas indicam que, para as mulheres ouvidas neste trabalho, a maternidade, mesmo nos casos em que é desejada, não é concebida de qualquer forma, mas envolve um contexto ideal, no qual ela seria bem-vinda. Portanto, entre as mulheres que tinham o desejo de ter filhos, o aborto esteve ligado a uma identificação do momento da gravidez como um momento impróprio (6/8) para se ter filhos. Um conjunto de fatores foi elencado para designar o momento como impróprio. Um desses fatores, que, aliás, é abordado com veemência nas falas das entrevistadas, é o relacionamento distante do ideal para criação de uma criança (7/8). Algumas das mulheres não queriam que 0 parceiro fosse 0 pai da criança (3/3). Há, também, o receio de que o parceiro não estivesse presente durante a criação da criança (2/3) e aquelas cujos parceiros não queriam ter o filho (3/ 3 ), além das que tiveram relações pontuais com o parceiro (3/3), incluindo aqui as que não sabiam quem era o pai da criança (2/2). Isto indica que as mulheres entrevistadas compartilhavam um ideal de relacionamento propício para se ter filhos: seria um relacionamento estável e afetuoso, em que ambos os parceiros desejassem ter aquela criança.

Mas em um determinado momento eu pensei em ter uma produção independente, mas, aliado a isso, eu sempre pensava também que o ideal é você ter um filho com uma família estruturada, o ideal. Aí claro que, no meio do caminho, se tiver de separar, mas eu acho que o ideal é uma família, pai, mãe, filho, sou conservadora. (Azaleia)

Em trabalho publicado por Lívia Krause ARNAUD (2008), essas mesmas questões foram identificadas, atribuindo-se a elas um compartilhamento social da relação entre maternidade e casamento ou união estável. A autora destaca a maleabilidade de moralidades em relação ao aborto que, embora muitas vezes aceito, é também condenado em caso de "banalização". A autora também constata o compartilhamento da ideia de um momento ideal para a maternidade, que envolveria, entre outros aspectos, o relacionamento estável com o parceiro, coerente com uma ideia "tradicional" de família.

Há, também, fatores que não têm relação com o parceiro e que contribuíram para a decisão pelo aborto, como a preocupação em decepcionar os familiares (2/2), a instabilidade financeira (5/5), a preocupação com a saúde do feto (1/1), e a ideia de que um filho naquele momento atrapalharia os planos de futuro (3/3). A preocupação em decepcionar os familiares indica um constrangimento sofrido pelas mulheres em terem exposto o fato de que são sexualmente ativas. Isso aparece na fala de Gerusa em relação ao primeiro aborto, quando tinha 18 anos e estava inserida em um contexto familiar extremamente religioso. Mas também aparece na fala de Ester, a qual já tinha mais de 40 anos e emprego estável. Essas experiências indicam uma vergonha sentida por mulheres por engravidarem fora do casamento. 
É no relacionamento também, mas, assim, eu tinha acabado de sair da casa dos meus pais, e minha família é uma família mais religiosa, mais tradicional e nunca tinha acontecido nada de uma das filhas do meu pai engravidar e seria um trauma para eles. (Ester)

Bourdieu (1998) afirma que, enquanto para o homem a honra é algo a ser conquistado através de diversos quesitos e provas, para a mulher, a honra é algo que deve ser preservado. Uma das principais formas que a mulher tem de não deixar escapar a honra é envolver-se sexualmente com a menor quantidade de parceiros possível. A gravidez não planejada e fora do casamento constituiria, assim, uma evidência da atividade da vida sexual da mulher e, portanto, uma ameaça à sua honra. O aborto como forma de ocultar o exercício da sexualidade da mulher aparece também em outros trabalhos (Margareth M. ARILHA, 2012; Ivanilda Lacerda PEDROSA \& Telma Ribeiro GARCIA, 2000; Lúcia RIBEIRO, 1994; Fernanda Pivato TUSSI, 2010).

Pelo que indicam os relatos das entrevistadas, a sexualidade feminina está um pouco mais independente da maternidade, mas a associação entre a maternidade ideal e a constituição de uma família (4/6) permanece forte.

Sim, [...] eu acho que eu gostaria de ser mãe, eu fico pensando nisso. Antes de tomar a decisão eu pensava nisso, [...] sabe, eu gostaria de ser uma mãe massa. [...] Ah, talvez esse seja o momento, talvez não seja, mas se esse é o momento quais situações que eu tenho que criar, que ambiente que eu tenho que criar para ele ser realmente digno disso?' (Geovanna)

Muitas das motivações citadas nas entrevistas aparecem também em trabalhos de outros autores. Aspectos como a falta de apoio do companheiro, instabilidade do relacionamento, momento de vida, dificuldades financeiras e constrangimento em revelar que são sexualmente ativas são comuns à nossa pesquisa e à literatura sobre o assunto de forma geral. ${ }^{5}$ Nas falas de nossas entrevistadas, a ideia de que um filho naquele momento atrapalharia os planos de futuro é mais recorrente do que na literatura, o que poderia ter relação com o fato de que a maior parte das interlocutoras pertencia à classe média e tinha contato com os discursos feministas. A literatura aponta que, de modo geral, entre pessoas de classe média ou alta, surgem mais justificativas de ordem subjetiva, como planos para o futuro (Rosely G. COSTA, Ellen HARDY, Maria José D. OSIS \& Aníbal FAÚNDES, 1995) e aspectos vinculados à sua própria vontade ou planejamento de vida, ${ }^{6}$ do que ocorre entre pessoas de classe popular. Nas raras ocasiões em que estas mulheres são convidadas a falar da experiência de abortamento, elas o fazem com a justificação de que não teriam condições econômicas de sustentar aquela criança.

Muitas mulheres consideram que não criariam bem uma criança naquele momento (Heather D. BOONSTRA, Rachel Bensol GOLD, Cory L. RICHARDS \& Lawrence B. FINER, 2006). Seja porque estavam numa fase de início profissional, como Geovanna, ou por não confiar na presença do pai na criação, como Geórgia em seu segundo aborto, algumas das motivações elencadas pelas mulheres que participaram do presente estudo tiveram relação

\footnotetext{
${ }^{5}$ Outras pesquisas que analisam as motivações de mulheres que interromperam a gravidez e que encontram, de forma geral, resultados semelhantes aos nossos: Rafael SANSEVIERO (2003); Arnaud (2008); Mariza Silva de OLIVEIRA, Izabel Cristina Falcão Juvenal BARBOSA \& Ana Fátima Carvalho FERNANDES (2005); Vanessa do Nascimento PEREIRA, Flávia Aelo de OLIVEIRA, Nadirlene Pereira GOMES, Telmara Menezes COUTO \& Gilvânia Patrícia do Nascimento PAIXÃO (2012); Bárbara Angélica Gómez PÉREZ, Nadirlene Pereira Gomes, Maria de Fátima de Souza SANTOS \& Normélia Maria Freire DINIZ (2013); Susana ROSTAGNOL (2005); Tussi (2010).

${ }^{6}$ Os seguintes estudos tratam das diferenças entre classes nas experiências e motivações do aborto: Maria Luiza HEILBORN, Cristiane da Silva CABRAL, Livi FARO, Fabíola CORDEIRO \& Rogério Lopes AZIZE (2012).
} 
com uma preocupação com a própria criança. Isso também foi abordado por Greice MENEZES \& Estela AQUINO (2009), que argumentaram que, nesses casos, o aborto seria significado como um "mal menor".

A preocupação com o futuro da criança - manifestada pelas mulheres - permite relativizar a oposição entre o "interesse do feto" e o "interesse da mulher", muito difundida no debate político sobre o aborto, uma vez que o aborto muitas vezes ocorre diante da preocupação com a qualidade de vida da futura criança. Quando não se quer ter uma criança em condições que se julga inadequadas, tanto para si própria, quanto para o bebê, o desejo da mulher e o bem-estar da criança convergem.

Assim, ao invés de uma ruptura com o ideal de maternidade, a esfera das experiências das mulheres aqui entrevistadas indica justamente a identificação com esse "ideal", que pode se definir a partir da representação mais tradicional de família, mas não apenas isso. A noção de responsabilidade, a preocupação com o bem-estar dos filhos ou a preocupação consigo mesma - com seu projeto de vida ou seu preparo para desempenhar o papel de mãe - são elementos presentes na ideia da maternidade compartilhada pelas entrevistadas.

\section{A decisão}

Na maioria das vezes houve dúvida ou recuo ao longo do processo de decisão em relação à gravidez indesejada. Algumas das entrevistadas, entretanto, relataram não ter sentido nenhuma dúvida quanto à interrupção da gravidez (4/5). A decisão foi mais fácil para quem não gostava do parceiro (1/1), nos casos em que as mulheres tinham clareza de que não queriam ser mães $(2 / 3)$, e para uma das entrevistadas, que não sabia quem era o pai (1/1). Esta última, a Azaleia, afirmou que já havia pensado previamente na situação e decidido que abortaria (1/1). A maioria das participantes, porém, vivenciou algum nível de dúvida. Para as mulheres que tiveram pouca dúvida (4/ 4), o principal fator que pesou pela continuidade da gravidez foi o desejo de ter filho (4/ 4). No entanto, outras questões se fizeram mais importantes na decisão: falta de tempo para pensar (1/1), preocupação com a saúde do feto $(1 / 1)$, parceiro que não queria ter o filho (1/1), e não querer que o parceiro fosse o pai da criança $(1 / 1)$. Alguns processos envolveram multa dúvida (2/2). Entre estes, os fatores que favoreceram a continuidade da gravidez foram o desejo de ter filho (1/1) e as concepções religiosas (1/1). No entanto, outros aspectos pesaram mais e estavam relacionados com o momento de vida (2/2). Em um dos casos, havia uma importante instabilidade financeira (1/1), e, no outro, a entrevistada vivia uma situação de violência doméstica (1/1) da qual procurava se desvincular. Muitas vezes, o processo de decisão é conflituoso.

Eu fui, fiz exame de sangue, positivo, 'bom, e agora?'. Eu nem duvidei, falei 'gente, eu não vou ter esse filho não, eu quero muito, mas não', por quê? Meu ex-namorado era gente boa, [...] porém [...] tinha várias coisas que ia ser muito difícil, muito difícil mesmo e um filho é pra sempre e eu antes falava 'O problema nem seria filho, problema é o pai nesse caso pra mim', [...] mas ia ser uma tortura pra mim. [...] Teve momentos em que 'Pô, seria lindo, mas...', mais pelo filho do que não, nossa, enfim, [...] daí falei 'Não, eu vou abortar sim, com certeza'[...]. (Francisca)

Como eu já sabia que naquelas condições se eu ficasse grávida eu poderia fazer aborto, então, assim, quando eu descobri eu não tinha dúvida, por toda a situação que eu te contei, que eu não sabia exatamente quem era, porque eu ganhava pouco, morava na república, foi uma decisão já, quase que ela já estava pronta se acontecesse. (Azaleia)

Assim, os processos decisivos pareceram ser muito variados. A presença ou não da dúvida, bem como a intensidade dela, tem relação tanto com o momento e contexto da 
gravidez, quanto com vivências e posicionamentos anteriores. Geralmente, quando as mulheres indicam um desejo pela maternidade, a dúvida está presente, seja ela pequena ou grande. Nos dois casos em que as mulheres disseram não sentirem vontade de ser mães, a decisão estava quase que tomada a priori.

A figura dos parceiros apareceu em todos os casos (nenhuma, pouca e muita dúvida), o que indica que o relacionamento entre a mulher e o pai da criança, os posicionamentos do parceiro de forma geral e em relação à gravidez e as características dele percebidas pela mulher influenciam diretamente na tomada de decisão.

\section{O papel do feminismo na decisão}

Como muitas das participantes tinham envolvimento com os movimentos feministas, o papel do feminismo na decisão pelo aborto se mostrou algo significativo. O assunto surgiu de forma espontânea na maioria das entrevistas, e foi abordado, seja pelas entrevistadas, seja pelas pesquisadoras, tanto como uma corrente de pensamento acadêmico, quanto como movimento social. Os diferentes tipos de feminismo e as disputas internas a esse campo não foram relevantes nos discursos das entrevistadas.

O feminismo aparece tanto como influência na decisão $(3 / 3)$, uma vez que ele permitiu às mulheres que considerassem a possibilidade de fazer 0 aborto (3/ 3); quanto como suporte moral para a sustentação da decisão (5/7), uma vez que permitiu às mulheres enxergar o aborto como moralmente aceitável (5/7).

Se eu não fosse feminista [...] desde cedo, com certeza eu talvez tivesse titubeado muito pra tomar minhas decisões, me sentido culpada, vir carregando isso o tempo inteiro, fazer um muro de lamentações e deprimir. O feminismo marcou e marca a minha vida assim inteiramente, principalmente na questão de liberdade, da minha liberdade em tudo, nas minhas relações, no meu modo de ver o mundo. (Geórgia)

Dessa forma, pode-se compreender que, mesmo estando inseridas em uma sociedade que santifica o feto e, principalmente, a maternidade (BADINTER, 1985), o contato com as discussões feministas sobre o direito de a mulher decidir sobre o próprio corpo e o próprio destino auxiliou as mulheres a considerarem o aborto como algo possível.

Além disso, o feminismo também surgiu, e de maneira mais forte, como suporte moral para a sustentação da decisão (5/7). Sendo o aborto um tema polêmico e estigmatizado (Elizabeth FARFÁN, 2006), decidir interromper a gravidez pode gerar um sentimento de que se está fazendo algo errado. No entanto, a partir do contato com os argumentos "pró-escolha", questões como a negação da maternidade compulsória e a defesa da autonomia da mulher diante da própria vida tornaram-se familiares para as nossas entrevistadas. Diante deste cenário, o feminismo permitiu enxergar o aborto como moralmente aceitável (5/7), evitando ou diminuindo o sentimento de culpa muito citado nas pesquisas sobre o assunto (Gláucia Rosana Guerra BENUTE, Roseli Yamamoto NOMURA, Pedro Paulo PEREIRA, Lucia Mara Cristina SOUZA \& Marcelo ZUGAIB, 2009); Rostagnol, (2005); Juliana Silva PONTES (2006).

Apesar de o envolvimento com os debates feministas ter auxiliado na consideração do abortamento e na aceitação da decisão, ele não eximiu de conflitos os processos vividos pelas mulheres. As dúvidas e recuos são evidência disso.

\section{A rede de relações}

A partir do momento em que a mulher se vê diante de uma gravidez indesejada, alguns atores são acionados e uma rede de apoio é formada. Esse processo engloba desde os interlocutores com quem se conversa para a construção da decisão sobre a 
continuidade ou não da gravidez, até os atores que auxiliam na execução do aborto, como já sugerido por outros autores. ${ }^{7}$

Algumas entrevistadas disseram ter se tratado de decisões mais individuais (4/ 4). No entanto, para a construção da decisão, houve, com frequência, a presença de interlocução com o parceiro $(4 / 5)$ a partir da ideia de que este dividiria com a mulher a vivência da parentalidade. Em contrapartida, e com maior recorrência, houve também aquelas que não dialogaram com o parceiro para a decisão - ausência de interlocução com o parceiro (6/6). Entre os parceiros que participaram da decisão, vários pressionaram para que a gravidez fosse interrompida (3/4), um pressionou para que a gravidez fosse continuada (1/1) e um apoiou a decisão da mulher $(1 / 1)$.

No caso de Geovanna, por exemplo, o parceiro exerceu uma pressão para que a gravidez fosse interrompida:

[...] na verdade, ele não queria, não queria ter um filho, aí falou que era eu que ia decidir na verdade, mas que por ele se eu quisesse tirar ele até preferiria porque ele não queria naquele momento um filho, mas se eu decidisse ter, então teria. (Geovanna)

O caso de Gerusa, que fez dois abortos, é um bom exemplo de uma decisão que conta e outra que não conta com a interlocução do parceiro. Em seu primeiro aborto, Gerusa era jovem, vivia um contexto de violência, e não sabia quem era o pai da criança. Nessa ocasião, Gerusa ficou muito restrita às opiniões da cunhada, sua única interlocutora, e com a qual não tinha relação íntima. O segundo aborto de Gerusa ocorreu 20 anos depois. Ela estava casada e já tinha clareza de que não queria ser mãe. Na segunda situação, houve uma interlocução com o parceiro, o qual apoiou sua autonomia de decisão. Ela soube que qualquer que fosse o desfecho daquela gravidez, ela teria esta segurança. Ela foi, no segundo aborto, a única das entrevistadas que se sentiu bem com o posicionamento do parceiro no momento de decisão, uma vez que ele se manteve aberto tanto ao aborto quanto à criação da criança, e apoiou-a em seu poder de decidir.

Mas foi muito tranquilo do ponto de vista de negociar, ele pensou na possibilidade, talvez até me reforçando, será, eu também senti como apoio assim, 'se você quiser eu também topo, faça o aborto ou aquilo que você quer mesmo assim'. Então eu tive tranquilidade, acho que foi isso, foi muito diferente do contexto de lá, eu tive possibilidade de poder escolher, se eu quisesse ou se eu não quisesse, teria condições pra ter e poderia optar por não ter. Então eu acho que foi tranquilo nesse aspecto. (Gerusa)

Houve também a interlocução com referências femininas (3/3). Nestes casos, pareceu surgir uma cumplicidade entre mulheres relacionada à decisão diante de uma situação, que, embora comum, é apresentada nos discursos das entrevistadas como algo socialmente condenável, que é a da gravidez indesejada.

Mas como essa cunhada minha já sabia muitos meandros, ela foi uma que [...] me influenciou muito na decisão de fazer o aborto naquele momento, porque eu acho que apesar de eu ver que ia ser todo um transtorno eu manter aquela gravidez sem conseguir determinar quem era o pai, desempregada, com toda essa estrutura familiar de violência [...], evangélica, mesmo assim eu não estava topando muito fazer o aborto. [...] Então fazer um aborto era um pecado pra mim naquele contexto. Mas eu lembro que teve uma hora aí, mas aí tudo encaminhou, ela foi falando 'Não, você não tem

${ }^{7}$ Alguns trabalhos também debatem o envolvimento de outros atores no processo do aborto: Diniz \& Medeiros (2012); Pedrosa \& Garcia (2000); Zannety Conceição Silva do Nascimento SOUZA, Normélia Maria Freire DINIZ, Telmara Menezes COUTO \& Solange Maria dos Anjos GESTEIRA (2010). 
como ter esse filho, vai ser muito pesado pra você', eu sei que ela teve um trabalho de convencimento muito forte. (Gerusa)

Além da interlocução no momento de decisão, a rede é formada, e de maneira mais forte, no processo de execução do abortamento. Em algumas situações, a interlocução com o parceiro para a concretização do aborto (3/3) é fundamental, sendo que, entre as falas das entrevistadas, o parceiro atua principalmente na conexão com o mundo público na busca do Citotec. ${ }^{8}$

Também houve as que não tiveram interlocução com o parceiro para concretização do aborto (6/8). Rose, por exemplo, engravidou depois de uma relação pontual com um conhecido. Pensou em conversar com ele sobre o aborto para solicitar ajuda financeira para o pagamento do procedimento. No entanto, abordou essa possibilidade em conversas com um amigo e com sua terapeuta, e ambos a aconselharam a não contar para o rapaz, uma vez que não faria sentido "você fazer uma pessoa sofrer com uma decisão que ele não tem mais poder de escolha" (Rose).

E engraçado, [...] na mesma época eu estava em terapia, [...] e contei pra ela, ela, assim como o meu amigo, pensou a mesma coisa. Por que eu não contaria para o cara? Bondade? Gente, que bondade é essa que esse povo está querendo que eu tenha? [...] Aí a mulher é tão subjugada, eu tenho que ser boa por uma pessoa que, sinceramente, aconteceu, ok, somos ambos responsáveis, mas ele não vai saber, gente [...]. Mulher, até no momento, tem que prezar por uma família que nem existe, tem que preservar o homem, preservar a família. (Rose)

A interlocução com figuras femininas para concretização do aborto (6/8) foi mais expressiva do que com os parceiros, tanto para conseguir o remédio, quanto para acompanhar o processo. Parece haver, neste momento, uma confiança em outras mulheres muitas vezes maior do que nos parceiros. Essa situação parece levar a um fortalecimento de uma cumplicidade entre as mulheres, que trocam receitas de como abortar e apoiam umas às outras. ${ }^{9}$ Dentro da rede formada, circulam conhecimentos sobre os procedimentos, apesar da ilegalidade e do estigma característicos da questão (DINIZ \& MEDEIROS, 2012; SOUZA et al., 2010).

[...] dentro das pessoas que eu selecionei naquele espaço que era uma pessoa que eu podia confiar era ela, eu já sabia que ela já tinha feito, exatamente, sabia que ela era a pessoa que naquele momento ia ser solidária comigo nesse ponto de vista de apoiar se eu topasse fazer um aborto, que teria conhecimento, inclusive, que eu não tinha de onde acionar os locais de compra, que procedimento fazer pra abortar [...]. (Gerusa)

Dentre as mulheres que tiveram interlocução com figuras femininas, algumas acionaram participantes do movimento feminista para a concretização do aborto (3/3).

Aí você coloca a pílula [...], eu deitei [...], tem tipo umas horas que você tem que passar, que aí você vai começar com o sangramento; [...] Até foi a amiga enfermeira que fez isso tudo, porque eu fiquei 'liiihhh, não', e é muito doido como você se entrega também às mulheres que estão aí te bancando total, de você estar ali, está teu corpo entregue ali, isso é muito forte das mulheres, muito foda. (Francisca)

${ }^{8}$ Citotec ou Misoprostol é o medicamento utilizado para realização do aborto. Atualmente, é proibido no Brasil, estando restrito aos meios de tráfico de substâncias. Sobre a presença do parceiro, ver Heilborn et al. (2012).

${ }^{9}$ Isso também foi encontrado nos trabalhos de Pontes(2006) e Sanseviero (2003). 
No momento de execução do abortamento, esta rede que se forma entre as mulheres adquire muita importância (PONTES, 2006). Tanto o conhecimento sobre como se aborta, como os percursos para se conseguir o medicamento, até uma companhia ou apoio na hora do procedimento são parte do discurso das entrevistadas. A própria situação de clandestinidade impele as mulheres a trocarem informações e se apoiarem. Isto indica que, apesar da ilegalidade, ou até mesmo potencializada por ela, há uma cultura do aborto no país. ${ }^{10}$ Assim, diante de uma lei punitiva e de uma sociedade que valoriza a maternidade de forma a quase vinculá-la à divindade, ${ }^{11}$ as mulheres podem construir entre si formas e estratégias de enfrentarem diversos desafios que se impõem em suas trajetórias de vida diante de uma gravidez indesejada.

\section{Sentimentos}

A experiência do aborto parece ocasionar uma diversidade de sentimentos. Algumas entrevistadas sentiram medo (2/2), seja medo de morrer $(2 / 2)$, seja medo de serem denunciadas (2/2), o que tem relação estreita com a situação de clandestinidade do aborto no país. $\mathrm{O}$ fato de ter que agir secretamente, manter sigilo e atuar com cautela é importante nas vivências das mulheres.

Então eu fiquei com muito medo no processo, eu acho que eu fiquei com esse sentimento de culpa de que eu estava fazendo alguma coisa errada, [...] a coisa do pecado ainda muito vinculada, a coisa da religião, e fiquei com muito medo de todo esse imaginário que tem, que fazer aborto é muito perigoso, que você pode morrer, então isso tudo também passa na nossa cabeça, principalmente quando a gente faz o aborto dessa forma assim tão clandestinamente. Medo de tudo, de alguém descobrir ou ser presa porque é crime, é uma coisa proibida. (Gerusa)

Algumas também vivenciaram culpa (3/3), muitas vezes relacionada a questões religiosas (2/2).

[...] pra mim foi meio difícil [...]. Na minha cabeça nunca tinha passado eu fazer uma coisa dessa, nunca, nunca pensei em fazer isso, e pela minha formação também, [...], então para mim foi difícil. Depois eu fiquei meio depressiva porque fiquei naquele sentimento de culpa, de que não deveria ter feito isso, porque que eu fiz, não tinha como mais, não tinha recurso mais. Então, assim, é o que eu te falo, hoje eu não faria não, com minha cabeça de hoje não faria não. (Ester)

Além disso, houve um sentimento de alívio bastante recorrente (4/5). Isso coloca em questão, como salienta Gerusa, os discursos que circulam socialmente de que a mulher sofre muito ao abortar.

E eu não tive essas coisas que as pessoas falam assim 'Ah, nunca é tranquilo fazer um aborto e tal'; pra mim foi, 'vacilei, não quero, foi um erro, vou tirar'. [...] nesse segundo assim, não tive nenhum conflito como eu tive no primeiro, que no momento ali eu queria desistir [...]. Eu acho que nesse segundo não, assim, foi, fiz e tudo deu certo e depois eu só senti alívio que acabou, deu tudo certo, não senti nenhum peso assim. [...] Aí eu estou falando isso porque eu já ouvi muito esse discurso das pessoas falarem assim 'Nunca é tranquilo, sempre é um peso pra mulher fazer'. [...] Não, não tive, hoje em dia não tenho o menor arrependimento de ter feito os dois abortos que eu fiz. (Gerusa)

\footnotetext{
${ }^{10} \mathrm{O}$ argumento de que existe no Brasil uma cultura do aborto é defendido por Diniz \& Medeiros (2012)

"Sally SHUTTLEWORTH (1990) discute a articulação entre maternidade e a dimensão do sagrado.
} 


\title{
Falar sobre o assunto
}

Segundo Heilborn et al. (2012), na classe média, o apoio ao aborto é mais frequente, de forma que a mulher não sente tanta necessidade de omitir a gravidez, pode buscar os melhores meios para interrompê-la e também tem a possibilidade socialmente legitimada de contar sua experiência. Esse não foi o caso, no entanto, das entrevistadas do presente trabalho. Pelo contrário, o silêncio sobre a experiência de aborto que viveram foi algo recorrentemente citado pelas mulheres. Elas falam pouco sobre o assunto, ou, ao menos, com poucas pessoas (5/5). Algumas vezes, não compartilhar esta vivência pode gerar um sentimento grande de solidão (2/2).

\begin{abstract}
Ah, eu me senti muito sozinha, [...] Eu não podia sair contando isso para ninguém, era uma coisa que eu tinha que guardar pra mim pra sempre, que eu não podia publicizar isso, comentar isso com um grupo de amigos e contar essa experiência, saber outras pessoas próximas que passaram pela mesma coisa [...] Não ia sair falando sobre isso e acho que eu nem ia me sentir à vontade de estar falando sobre isso, sabendo que eu poderia passar [...] por um julgamento de outra pessoa. Então, acabei me sentindo, assim, muito sozinha, achei que eu estava arrependida, sentindo um pouco de culpa, muita tristeza, assim, nesse estado. (Geovanna)
\end{abstract}

Um dos fatores que leva a isso é o contexto de clandestinidade. Com receio de serem denunciadas, elas restringem as pessoas com as quais conversam sobre o assunto. A ilegalidade do aborto não impede que ele seja feito, mas o situa na esfera do segredo, do privado, podendo atuar na reprodução da subordinação feminina, como salienta Rostagnol (2005).

El silencio se constituye en un indicio de subordinación. Las mujeres hacen algo en secreto/en privado - eso les está permitido - deben guardarlo en la intimidad; no debe tomar estado público. La división público/privado que ha sido uno de los pilares que sustenta la organización social, especialmente en la modernidad, refuerza las relaciones de género que colocan a las mujeres en un el lugar de la subordinación. La culpa cuya contracara puede ser la censura social - se erige como el instrumento para evitar que tome estado público. La culpa es entonces el instrumento de poder que mantiene a las mujeres aisladas - cada una con su(s) propio(s) aborto(s) - y sometidas: hicieron algo malo y deben pagarlo, ocultándolo (ROSTAGNOL, 2005, p. 9).

A análise das entrevistas que foram objeto do presente estudo revela, no entanto, que o silêncio sobre o aborto não teve relação somente com a ilegalidade do procedimento. Restringir o escopo de pessoas com as quais se conversa sobre o assunto pode ter como finalidade preservar-se (3/4) - o que ultrapassa o sentido jurídico, e abarca uma preservação da intimidade - e não criar polêmica (3/4). Para não passarem por momentos constrangedores de julgamento, elas preferem o silêncio. Gerusa já passou por uma situação em que uma amiga reagiu de forma violenta à questão.

Por exemplo, que eu fui contar pra uma amiga minha [...] e ela tem uma vida sexual muito liberada [...]. E eu lembro que um dia nós estávamos no centro bebendo e tal, e ela já teve seis filhos, [...] filhos de pais diferentes, aí eu fui contando que eu tinha feito dois abortos e tal, na hora que eu falei isso, nossa! Ela mudou, 'O que é isso, que absurdo!', ela chegou assim a ser violenta comigo, [...] 'Você é uma assassina', [...] eu precisei falar 'Olha, você para agora ou eu vou embora e a gente acaba a nossa história por aqui', pra poder dar um basta de tanto que ela começou falar uma série de coisas ali em público, [...] então essas ações assim também vão mostrando que você tem que ficar um pouco na sua. (Gerusa) 
Esta fala de Gerusa demonstra uma situação em que a mulher que abortou não se sente culpada ou não necessariamente reconhece um grande sofrimento em sua experiência, mas evita trazer o assunto à tona por já ter passado por situações em que fora julgada moralmente e que a fizeram se sentir desconfortável.

O aborto, então, é um "tabu relativo", ${ }^{12}$ uma vez que pode ser um assunto do qual pouco se fala, mas é uma ação comum. Ao mesmo tempo, o fato de várias falarem com figuras femininas sobre o aborto indica que, em algumas relações, especialmente entre mulheres, o assunto é frequente. O aborto configura, assim, um espaço de transição entre a condenação pública e a tolerância privada. ${ }^{13}$

Diante deste contexto, a situação da entrevista tornou-se um dos poucos momentos para as mulheres falarem de suas experiências. Ao descreverem suas vivências, as participantes puderam resgatar a memória e ressignificá-las (TUSSI, 2010).

\section{Considerações finais}

O presente estudo tornou evidente que o processo de decisão pelo aborto envolve o contexto social, profissional, religioso e afetivo da mulher no momento, mas envolve, também, e fortemente, o parceiro e o relacionamento do casal. O modo como o parceiro reage à notícia da gravidez (nos casos em que ele fica sabendo) exerce um impacto fundamental no processo decisório. As características do parceiro, quando pensadas como incompatíveis com a parentalidade ideal, também se mostraram importantes nesse momento.

A interlocução com amigas e familiares se mostrou fundamental na tomada de decisão e na concretização do aborto. Diante de um cenário de clandestinidade, são formados laços de cumplicidade, especialmente entre mulheres, que estão presentes em todo o processo.

Raramente existiu um único motivo responsável pela decisão, mas há um conjunto de fatores que se inter-relacionam e fazem com que interromper aquela gravidez pareça a melhor opção.

Na maior parte dos discursos analisados, em consonância com o que é relatado na literatura sobre o assunto (ARNAUD, 2008), não houve predominância da recusa à maternidade, mas, sim, uma classificação do momento como impróprio para se ter filhos. Um fator intimamente relacionado a isso é o compartilhamento de um ideal de maternidade vinculado à constituição de família. Ao mesmo tempo em que se pôde identificar a permanência dessa visão mais tradicional de maternidade, observou-se também rupturas, como a afirmação recorrente de que ser mãe não é algo fundamental na vida da mulher e a valorização da profissão e da independência financeira para cuidar do filho.

Além disso, constatou-se que o contato com as ideias feministas teve papel importante na tomada de decisão e na concretização do aborto, tendo feito com que, para algumas entrevistadas, o aborto pudesse ser considerado uma possibilidade legítima. Mas, mais importante do que isso, as ideias feministas representaram um suporte para a decisão, amenizando possíveis sentimentos de culpa ou remorso. Ainda assim, o conflito esteve presente nas falas das entrevistadas, e muitas delas chegaram a desistir ou a reconsiderar a decisão em alguns momentos.

A localização social das entrevistadas não apareceu tão explicitamente em suas falas, mas notadamente marcou suas vivências de maneira significativa. Algumas mencionaram que estavam sem dinheiro na ocasião, mas, para nenhuma, a situação era muito extrema. A maior parte delas poderia contar com os pais ou outros membros da

${ }^{12}$ Tussi (2010, p. 31) utiliza esse termo.

${ }^{13}$ Esse argumento é defendido por Sanseviero (2003). 
família na criação da criança - se fosse o caso. Ainda assim, os relatos sugerem uma insegurança, um medo da morte e de serem denunciadas.

Os resultados mostram, também, que o ponto em que a ilegalidade do aborto mais afetou a experiência das mulheres entrevistadas foi no silêncio a respeito da questão. $O$ medo de serem denunciadas fez com que grande parte delas compartilhasse muito pouco suas vivências. Dessa forma, o aborto tornou-se um tabu em suas próprias vidas, o que evita que ele seja ressignificado. Esse silêncio é estimulado, também, pelo estigma em torno do aborto. O fato de ser ilegal não foi citado nenhuma vez como um motivo para não fazer o aborto. As análises das entrevistas indicam que a clandestinidade não inibe os abortos, mas faz com que eles sejam feitos de forma mais insegura e que não se possa falar sobre o assunto. Ressalta-se, assim, a necessidade da legalização do aborto, uma vez que a sua proibição afeta negativamente as mulheres, condenando-as ao medo e ao silêncio.

A polarização entre os interesses da mulher e os do feto, e, até mesmo, a polarização entre o desejo pela maternidade e a recusa da mesma, não fazem tanto sentido nas experiências de muitas mulheres que abortam, uma vez que a maior parte delas não recusa a maternidade de forma geral, mas, sim, em um momento e contexto específicos. ${ }^{14}$

As análises das entrevistas aqui realizadas sugeriram alguns comportamentos diante da gravidez não planejada similares aos já descritos na literatura. No entanto, o papel do contato com ideias feministas na tomada da decisão, na viabilização do aborto e no suporte psicológico às mulheres constitui contribuição importante e inovadora do presente trabalho.

\section{Referências}

ARILHA, Margareth M. "Misoprostol: percursos, mediações e redes sociais para o acesso ao aborto medicamentoso em contextos de ilegalidade no Estado de São Paulo". Ciência \& Saúde Coletiva, v. 17, n. 7, p. 1785-1794, julho 2012.

ARNAUD, Lívia Krause. Mulheres e Abortos: negociando moralidades. 2008. Dissertação (Mestrado em Antropologia Social), Programa de Pós-Graduação em Antropologia Social, Universidade Federal do Rio de Janeiro, Rio de Janeiro.

BARDIN, Laurence. Análise de conteúdo. Lisboa: Edições 70, 2011 [1977].

BADINTER, Elizabeth. Um amor conquistado: o mito do amor materno. Rio de Janeiro: Nova Fronteira S.A., 1985.

BEAUVOIR, Simone de. O segundo sexo. São Paulo: Difusão Européia do Livro, 1949.

BENUTE, Gláucia R. G.; NOMURA, Roseli Y.; PEREIRA, Pedro P.; LUCIA, Mara Cristina S. \& ZUGAIB, Marcela. "Abortamento espontâneo e provocado: ansiedade, depressão e culpa". Revista da Associação Médica Brasileira, v. 55, n. 3, p. 322-327, 2009.

BOONSTRA, Heather D.; GOLD, Rachel B.; RICHARDS, Cory L. \& FINER, Lawrence B. Abortion in Women's Lives. New York: Guttmacher Institute, 2006.

BOURDIEU, Pierre. A dominação masculina. 3.ed. Rio de Janeiro: Bertand Brasil, 1998.

COSTA, Rosely G.; HARDY, Ellen; OSIS, Maria José D. \& FAÚNDES, Aníbal. "A decisão de abortar: processos e sentimentos envolvidos". Cadernos de Saúde Pública, v. 1 1, n. 1, p. 97-105, jan./mar. 1995.

DINIZ, Débora \& MEDEIROS, Marcelo. "Itinerários e métodos do aborto ilegal em cinco capitais brasileiras". Ciência \& Saúde Coletiva, v. 17, p. 1671-1681, 2012.

FARFÁN, Elizabeth. "O corpo feminino como espaço público: o aborto e o estigma social no Brasil”. In: SEMINÁRIO INTERNACIONAL FAZENDO GÊNERO, 7, Florianópolis. Anais eletrônicos... Florianópolis, 2006. p. 1-8.

${ }^{14}$ Isso também é encontrado em Rostagnol (2005). 
FLICK, Uwe. "Entrevistas semi-estruturadas". In: Porto Alegre: Bookman, 2004. p. 89-108.

. Uma introdução à Pesquisa Qualitativa.

HEILBORN, Maria Luiza; CABRAL Cristiane da Silva; FARO, Livi \& AZIZE, Rogério Lopes. "Itinerários abortivos em contextos de clandestinidade na cidade do Rio de Janeiro - Brasil”. Ciência \& Saúde Coletiva, v. 17, n. 7, p. 1699-1708, jul. 2012.

MENEZES, Greice \& AQUINO, Estela. "Pesquisa sobre o aborto no Brasil: avanços e desafios para o campo da saúde coletiva". Cadernos de Saúde Pública, v. 25, n. 2, p. 193-204, 2009.

OLIVEIRA, Marilza Silva; BARBOSA, Izabel Cristina F. J. \& FERNANDES, Ana Fátima C. "Razões e sentimentos de mulheres que vivenciaram a prática do aborto". Rev. Reve., v. 6, n. 3, p. 23-30, set./dez. 2005.

PEDROSA, Ivanilda Lacerda \& GARCIA, Telma Ribeiro. "'Não vou esquecer nunca!': a experiência feminina com o abortamento induzido". Revista Latino-Americana de Enfermagem, v. 8, n. 6, p. 50-58, dez. 2000.

PEREIRA, Vanessa do Nascimento; OLIVEIRA, Flávia Aelo; GOMES, Nadirlene Pereira; COUTO, Telmara Menzes \& PAIXÃO, Gilvância Patrícia N. "Abortamento induzido: vivência de mulheres baianas". Saúde e Sociedade, v. 21, n. 4, p. 1056-1062, 2012.

PÉREZ, Bárbara Angélica G.; GOMES Nadirlene Pereira; SANTOS, Maria de Fátima S. \& DINIZ, Normélia Maria F. "Aborto provocado: representações sociais de mulheres". Revista de Enfermagem, UERJ, v. 21, n. 6, p. 736-742, dez. 2013.

PONTES, Juliana Silva. Histórias de vida de mulheres que provocaram abortamento: contribuições para a enfermagem. 2006. Tese (Doutorado em Enfermagem), Programa de Pós-Graduação em Enfermagem, Escola de Enfermagem Anna Nery da UFRJ, Rio de Janeiro.

RIBEIRO, Lúcia. "A experiência do aborto entre mulheres católicas". Perspectiva Teológica, v. 26, p. 227-233, 1994.

ROSTAGNOL, Susana. "Autonomia y subordinacion en el transito de las mujeres por el aborto clandestino". Otras Miradas, v. 5, n. 2, dez. 2005.

SANSEVIERO, Rafael. Condena, tolerancia y negación: situación del aborto en Uruguay. Montevideo: Universidad para la Paz, 2003.

SCAVONE, Lucila. "A maternidade e o feminismo: diálogo com as ciências sociais". Cadernos Pagu, v. 16, p. 137-150, 2001.

SHUTTLEWORTH, Sally. "Female Circulation: medical discourse and popular advertising in the Mid-Victorian Era". In: JACOBUS, Marry; FOX KELLER, Evelyn; SHUTTLEWORTH, Sally (Orgs.). Body/Politics: women and the discourses of Science. Nova York: Routledge, 1990. p. $47-$ 68.

SOUZA, Zannety Conceição S. N.; COUTO, Telmara Menezes \& GESTEIRA, S. M. A. "Trajetória de mulheres em situação de aborto provocado no discurso sobre clandestinidade", Revista Acta Paulista de Enfermagem, v. 23, n. 6, p. 732-736, 2010.

TUSSI, Fernanda Pivato. Aborto vivido, aborto pensado: aborto punido? As (inter)faces entre as esferas pública e privada em casos de aborto no Brasil. 2010. Dissertação (Mestrado em Antropologia Social), Programa de Pós-Graduação em Antropologia Social, Instituto de Filosofia e Ciências Humanas da UFRGS, Porto Alegre.

[Recebido em 06/08/2015,

reapresentado em $23 / 08 / 2016$

e aprovado em 23/02/2017]

1156 Estudos Feministas, Florianópolis, 25(3): 1141-1157, setembro-dezembro/2017 
Induced Abortion: A Study on Women's Experiences

Abstract: The present article relates the results of a research conducted between 2013 and 2015, which aimed to understand aspects of the experiences of women who have had illegal abortion. Eight women were interviewed. Unlike most studies on the theme, in the present investigation the majority of the women had high educational level and were involved with the feminist movement. We report the motivations for having an abortion, the details from the decisionmaking process and the influence of feminist ideas in the process of the women's decision.

Keywords: Abortion; Motherhood; Sexuality; Experience

Ana Beraldo de Carvalho (anaberaldopsi@gmail.com) é graduada e mestre em Psicologia Social pela Universidade Federal de Minas Gerais. Atualmente é doutoranda do Programa de Pós-Graduação em Sociologia da Universidade Federal em São Carlos (UFSCar). Tem experiência nas áreas de Psicologia Social, trabalhando com temas como gênero, feminismo, violência, criminalidade e políticas públicas.

Telma de Souza Birchal (tbirchal@gmail.com) é professora do Departamento de Filosofia da Universidade Federal de Minas Gerais. Concluiu o Doutorado em Filosofia pela Universidade de São Paulo, tendo realizado pós-doutoramento na Universidade de Oxford e em Notre Dame University. Integra o corpo de pesquisadores do Núcleo de Estudos do Pensamento Contemporâneo da FAFICH-UFMG.

Claudia Mayorga (mayorga.claudia@gmail.com) é doutora em Psicologia Social pela Universidade Complutense de Madri, com foco em estudo sobre gênero, política e feminismo. É professora do Departamento de Psicologia da Universidade Federal de Minas Gerais e do Programa de Pós-Graduação em Psicologia. Coordena o Núcleo de Ensino, Pesquisa e Extensão Conexões de Saberes na UFMG. Atualmente é pró-reitora adjunta de extensão da UFMG. 